\title{
Sharing Dan Workshop Manajemen Tata Kelola Open Journal System Pada Fakultas Universitas Boyolali
}

\author{
Rizki Wahyudi ${ }^{1}$, Rahmita Pratama ${ }^{2}$ \\ Universitas Amikom Purwokerto ${ }^{1,2}$ \\ Email: rizkiw@amikompurwokerto.ac.id
}

\begin{abstract}
ABSTRAK
Salah satu indikator kemajuan sebuah lembaga pendidikan (Perguruan Tinggi) adalah dengan adanya penelitian aktif oleh para dosennya yang dipublikasi melalui jurnal ilmiah. Oleh karena itu menulis jurnal menjadi kewajiban bagi setiap dosen selain mengajar mahasiswa yang merupakan bagian dari tri dharma perguruan tinggi. Jurnal kampus berbasis Open Journal System (OJS) juga menjadi bagian penting dari eksistensi kampuskampus baik nasional maupun internasional disamping sebagai wadah untuk menampung dan mempublikasikan ide dan inovasi. Jurnal yang baik dan diakui sebagai jurnal sekarang ini, harus mengikuti sistem OJS dalam pengelolaannya. OJS tersebut mengharuskan semua pihak meliputi dosen penulis (author), reviewer, tim redaksi dan editorial untuk menerapkan sistem penulisan karya ilmiah secara profesional dan terbuka, ditambah lagi dengan Peraturan Menristekdikti Nomor 9 tahun 2018 tentang Akreditasi Jurnal Ilmiah yang merupakan pengakuan resmi atas penjaminan mutu jurnal ilmiah melalui kegiatan penilaian kewajaran penyaringan naskah, kelayakan pengelolaan, dan ketepatan waktu penerbitan jurnal ilmiah. Namun tidak semua jurnal sudah di kelola dengan baik, diantaranya adalah jurnal yang berada di lingkungan Fakultas, Universitas Boyolali yang sudah memiliki ISSN dalam bentuk media cetak dan media online, namun kurangnya pengetahuan tim jurnal dalam manajemen tata kelola Open Journal System (OJS) mengakibatkan jurnal tidak mengalami perkembangan yang baik khususnya pada manajemen tata kelola sehingga berdampak kepada kualitas artikel yang diterbitkan, keterlambatan terbit. Untuk mempersiapkan jurnal yang berkualitas dan dapat terakreditasi nasional, Pengelola Jurnal di Lingkungan Universitas Boyolal membutuhkan pelatihan terkait manajemen tata kelola OJS agar dapat mengelola jurnal mulai dari proses penerimaan naskah, peer review, editing dan penerbitan sehingga dapat berkontribusi pada pada lingkup penelitiannya.
\end{abstract}

Kata Kunci: Open Jurnal System, Tata Kelola, Akreditasi

\begin{abstract}
One indicator of the progress of an educational institution (Higher Education) is the existence of active research by its lecturers published through scientific journals. Therefore, writing a journal becomes an obligation for every lecturer besides teaching students who are part of the tri dharma of higher education. Open Journal System (OJS) based campus journals are also an important part of the existence of national and international campuses as well as a forum for accommodating and publishing ideas and innovations. A good journal and recognised as a journal now must follow the OJS system in its management. The OJS requires all parties including author lecturers, reviewers, editorial and editorial teams to implement a scientific writing system professionally and openly, plus the Minister of Research and Technology Regulation No. 9 of 2018 concerning Accreditation of Scientific Journals which is an official recognition of journal quality assurance through scientific assessment activities fairness screening of manuscripts, the feasibility of management, and timeliness of scientific journal publishing. However, not all journals are well managed, including journals in the Faculty, Boyolali University which already has ISSN in print and online media, but the lack of knowledge of the journal team in the management of Open Journal System (OJS) governance results in journals did not experience a good development, especially on governance management so that it affected the quality of articles published, delays in publishing. To prepare quality journals that can be nationally accredited, Journal Managers in Boyolal University need training on OJS governance management so that they can manage
\end{abstract}


journals starting from the process of receiving manuscripts, peer reviews, editing and publishing so that they can contribute to the scope of their research.

Keywords: Open Journal System, Governance, Accreditation

\section{PENDAHULUAN}

Salah satu indikasi kemajuan sebuah lembaga pendidikan (Perguruan Tinggi) adalah dengan adanya penelitian aktif oleh para dosennya yang dipublikasi melalui jurnal ilmiah. Oleh karena itu menulis jurnal menjadi kewajiban bagi setiap dosen selain mengajar mahasiswa yang merupakan bagian dari tri dharma perguruan tinggi. Jurnal kampus berbasis Open Journal System (OJS) juga menjadi bagian penting dari eksistensi kampus-kampus baik nasional maupun internasional.

Jurnal yang baik dan diakui sebagai jurnal sekarang ini, harus mengikuti sistem OJS dalam pengelolaannya. OJS tersebut mengharuskan semua pihak meliputi dosen penulis (kontributor), reviewer, tim redaksi dan editorial untuk menerapkan sistem penulisan karya ilmiah secara profesional dan terbuka, ditambah lagi dengan Peraturan Menristekdikti Nomor 9 tahun 2018 tentang Akreditasi Jurnal Ilmiah yang merupakan pengakuan resmi atas penjaminan mutu jurnal ilmiah melalui kegiatan penilaian kewajaran penyaringan naskah, kelayakan pengelolaan, dan ketepatan waktu penerbitan jurnal ilmiah (Dikti, 2018).

Salah satu upaya pemerintah untuk meningkatkan mutu majalah ilmiah atau jurnal di Indonesia adalah menyelenggarakan program akreditasi terbitan berkala ilmiah. Program akreditasi ini bertujuan untuk meningkatkan kualitas dan kuantitas terbitan dalam komunitas ilmiah sehingga mampu berdaya saing dengan terbitan berkala ilmiah internasional. Pelaksanaan akreditasi terbitan berkala ilmiah dilatarbelakangi oleh perlunya optimalisasi hasil penelitian dari berbagai lembaga/institusi, baik lembaga penelitian, perguruan tinggi, maupun asosiasi profesi dalam rangka pengembangan keilmuan dan kebutuhan pembangunan di Indonesia.

Pada tahun 2014 telah ada ada kesepakatan antara LIPI dan DIKTI dalam menetapkan suatu pedoman akreditasi terbitan berkala ilmiah yang lebih menekankan pada penilaian penerbitan jurnal ilmiah secara elektronik. Peraturan tersebut diberlakukan per-April 2016. Artinya bahwa sejak ada peraturan baru yang ditandatangani bulan Agustus dan Septemper 2014, pengelola jurnal harus mulai melakukan transisi dari sistem pengelolaan dan penerbitan jurnal cetak (printed) ke terbitan jurnal elektronik. Untuk membangun sistem e-journal ini, LIPI dan DIKTI sepakat menetapkan program aplikasi yang digunakan untuk jurnal elektronik (e-journal) adalah Open Journal System (OJS) (Permenristekdikti, 2018; Lukman, 2015).

Namun tidak semua jurnal sudah di kelola dengan baik (Nashihuddin, 2017), khususnya dalam manajemen tata kelolanya mulai dari proses penerimaan naskah, peer review, editing dan penerbitan. Jurnal yang berada di Universitas Boyolali berjumlah 7 jurnal yaitu, jurnal DIGIKOM, jurnal Tropical Animal Science, Jurnal Bedah Hukum, Jurnal Ilmiah AgroTHP, EKOBIS : Jurnal Ilmu Manajemen dan Akuntansi, jurnal JITU : Journal 
Informatic Technology And Communication dan jurnal SENYUM BOYOLALI sudah memiliki ISSN dalam bentuk media cetak dan media online, namun kurangnya pengetahuan tim jurnal dalam pengelolaannya membuat jurnal-jurnal tersebut tidak mengalami perkembangan yang baik khususnya aspek manajemen tata kelola dan berdampak kepada kualitas artikel yang diterbitkan, untuk mempersiapkan jurnal yang berkualitas dan dapat terakreditasi, Jurnal di lingkungan Fakultas Universitas Boyolali membutuhkan sharing dan workshop terkait manajemen tata kelola OJS agar dapat berkontribusi pada pada lingkup penelitiannya penyerahan (submit) naskah, review, editing, hingga publikasi naskah dengan simulasi dengan tim. Journal online yang ada pada Universitas Boyolali, dapat di akses pada https://ejournal.uby.ac.id/. Berikut tampilan journal online pada Universitas Boyolali pada Gambar 1.
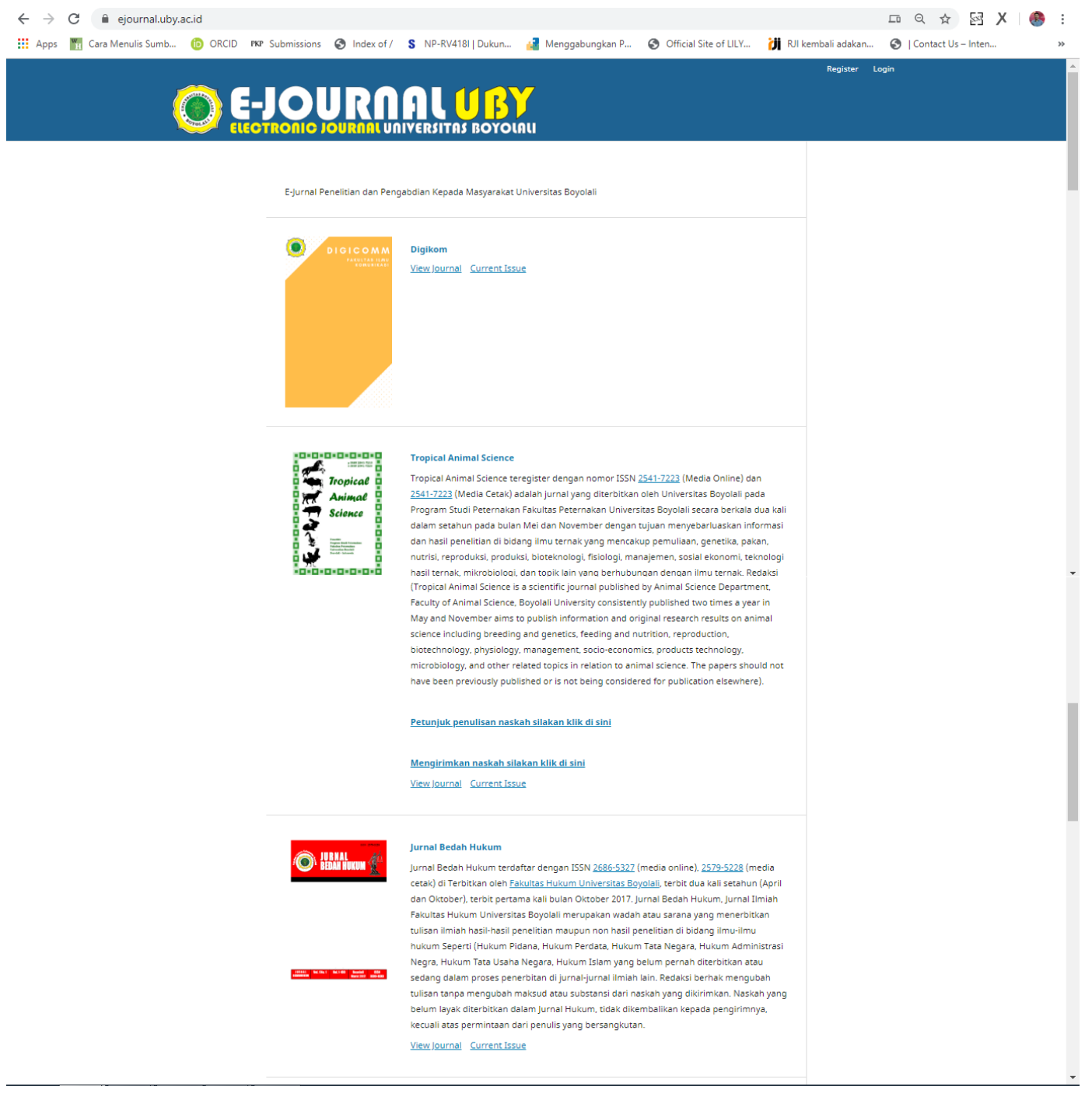

Gambar 1. Tampilan Portal Journal Online di Universitas Boyolali

Permasalahan yang dihadapi oleh mitra yaitu tim Jurnal pada Lingkungan Fakultas Universitas Boyolali adalah kurangnya pengetahuan terkait manajemen tata kelola jurnal media elektornik, 
mengakibatkan proses penerimaan naskah, peer review, editing hingga terbit belum memenuhi standar. Mengakibatkan mutu dan reputasi jurnal kurang baik.

Untuk mengatasi permasalahan kurangnya pengetahuan terkait manajemen tata kelola pada tim Jurnal pada Lingkungan Fakultas Universitas Boyolali, ini akan coba diatasi dengan mengadakan kegiatan sharing dan workshop manajemen tata kelola jurnal. Workshop akan di mulai dari penyerahan (submit) naskah, review, editing, hingga publikasi naskah dengan simulasi dengan tim. Maka dari itu, pengabdian ini akan memberikan informasi, pengetahuan mengenai cara manajemen tata kelola Jurnal pada Lingkungan Fakultas Universitas Boyolali.

\section{METODE}

A. Solusi yang Ditawarkan

Permasalahan terkait belum maksimalnya Terbatasnya pengetahuan tim jurnal Jurnal Tropical Animal Science terkait manajemen tata kelola Open Journal System "OJS" mulai dari proses penerimaan naskah, peer review, editing hingga terbit yang belum memenuhi standar.

Langkah-langkah yang akan dilakukan untuk untuk melaksanakan solusi yang ditawarkan dengan melakukan tiga tahap. Tahap pertama, melakukan koordinasi dengan dengan mitra pengabdian dalam hal ini Jurnal pada Lingkungan Fakultas Universitas Boyolali. Ketika proses koordinasi, juga akan dijelaskan bagaimana cara melakukan pelatihan, penentuan waktu pelatihan dan persiapan yang harus dilakukan oleh mitra dan pihak pengabdi. Tahap kedua, merupakan tahap pelaksanaan pelatihan. Pelaksanaan kegiatan Pendampingan manajemen tata kelola OJS kepada mitra Tim Jurnal pada Lingkungan Fakultas Universitas Boyolali. Pelatihan ini akan dibagi menjadi dua sesi, yaitu sesi pertama sharing terkait tata kelola manajemen Jurnal. sesi kedua Workshop terkait proses penerimaan naskah, peer review, editing hingga terbit. Tahap ketiga, Pendampingan manajemen tata kelola OJS. Tahap keempat, merupakan tahap evaluasi. Evaluasi akan dilakukan oleh pengabdi untuk mengetahui kelebihan dan kekurangan apa saja dalam proses pelaksanaan pelatihan manajemen tata kelola jurnal ini.

\section{B. Target Luaran}

Target luaran dari kegiatan pengabdian pendampingan setup dan manajemen tata kelola open journal system pada memiliki target luaran adanya perubahan dalam pemahaman ilmu pengetahuan dan teknologi yang terbagi sebagai berikut: Mitra dapat memahami dan dapat menerapkan manajemen tata kelola open journal system yang dimiliki sesuai.

\section{HASIL, PEMBAHASAN, DAN DAMPAK}

\section{A. Realisasi Pemecahan Masalah}

Untuk mengatasi masalah yang dihadapi oleh mitra, tim akan memetakan tahapantahapan penyelesaian masalahnya yang akan dilakukan untuk melaksanakan solusi yang ditawarkan dengan melakukan 4 tahapan. 
1. Melakukan koordinasi dengan dengan mitra pengabdian dalam hal ini Jurnal pada Lingkungan Fakultas Universitas Boyolali. Ketika proses koordinasi, juga akan dijelaskan bagaimana cara melakukan pelatihan, penentuan waktu pelatihan dan persiapan yang harus dilakukan oleh mitra dan pihak pengabdi.

2. Merupakan tahap pelaksanaan pelatihan. Pelaksanaan kegiatan Pendampingan manajemen tata kelola OJS kepada mitra Tim Jurnal pada Lingkungan Fakultas Universitas Boyolali. Pelatihan ini akan dibagi menjadi dua sesi, yaitu sesi pertama sharing terkait tata kelola manajemen Jurnal. sesi kedua Workshop terkait proses penerimaan naskah, peer review, editing hingga terbit.

3. Pendampingan manajemen tata kelola OJS.

4. Merupakan tahap evaluasi. Evaluasi akan dilakukan oleh pengabdi untuk mengetahui kelebihan dan kekurangan apa saja dalam proses pelaksanaan pelatihan manajemen tata kelola Jurnal pada Lingkungan Fakultas Universitas Boyolali.

\section{B. Khalayak Sasaran}

Rencana jadwal kegiatan dalam pengabdian di Jurnal pada lingkungan Fakultas Universitas Boyolali dapat dilihat pada Gambar 3. 
Jurnal Tropical Animal Science

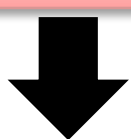

\section{Permasalahan}

Terbatasnya pengetahuan tim jurnal di lingkungan Fakultas Universitas Boyolali terkait manajemen tata kelola Open Journal System "OJS".

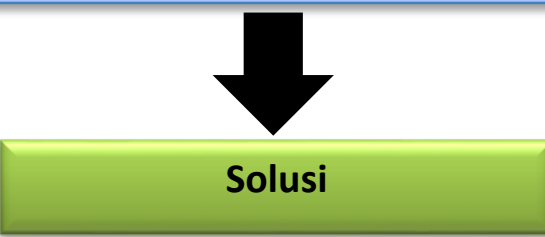

Sharing dan Workshop terkait tata kelola Open Journal System "OJS". Mulai dari penyerahan (submit) naskah, review, editing, hingga publikasi naskah dengan simulasi dengan pada tim jurnal di lingkungan Fakultas Universitas Bovolali

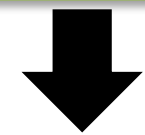

\section{TARGET LUARAN}

Mitra dapat memahami dan mengerti manajemen tata kelola penyerahan (submit) naskah, review, editing, hingga publikasi naskah pada Open Journal System "OJS" di lingkungan Fakultas Universitas Boyolali, sehingga dapat meningkatkan kualitas publikasi

Gambar 3. Gambaran Program Pengabdian yang akan ditransfer Kepada Khalayak Sasaran

Berikut dokumentasi kegiatan pelathan manajemen tata kelola OJS kepada mitra Tim Jurnal pada Lingkungan Fakultas Universitas Boyolali. 


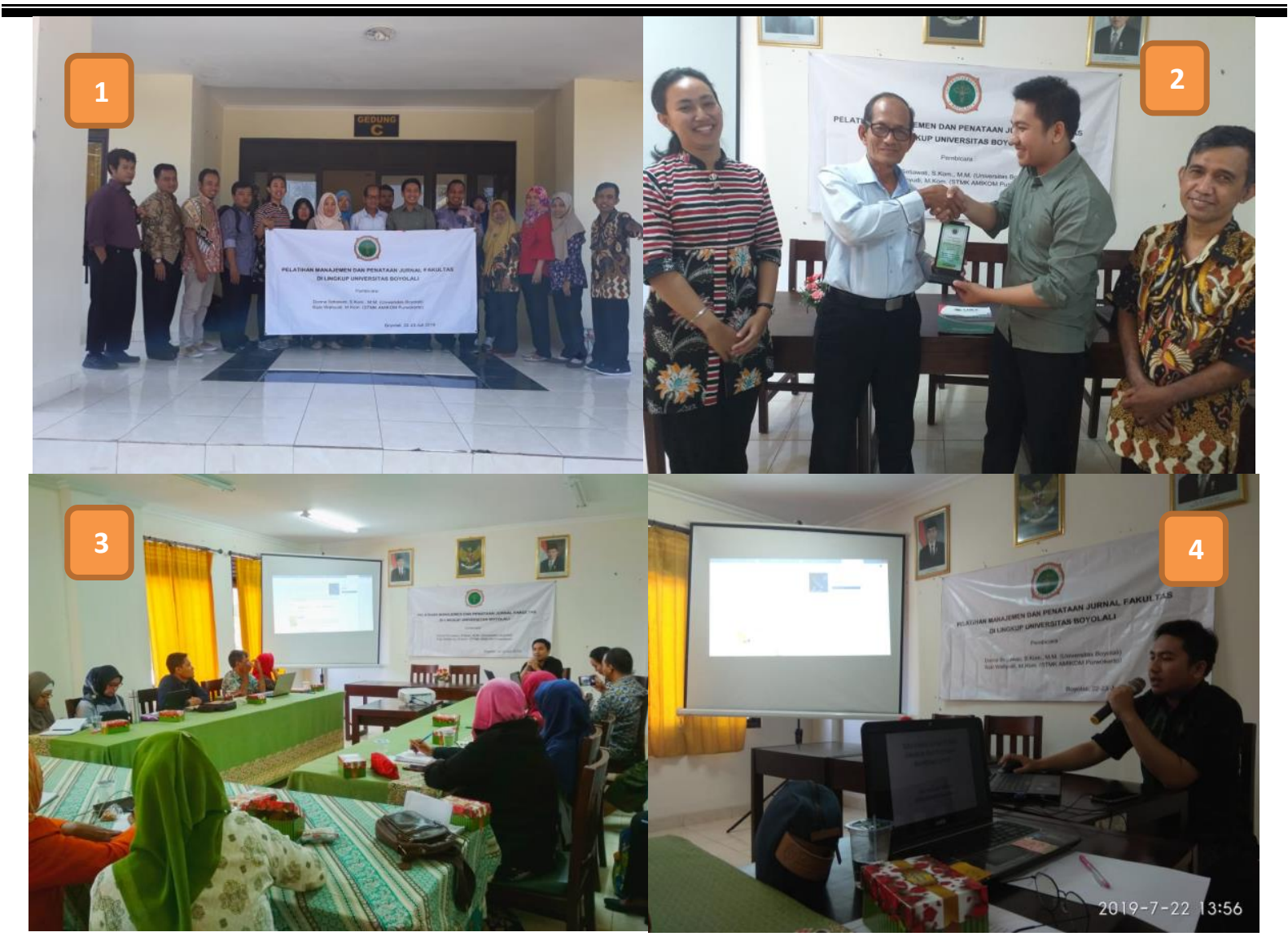

Gambar.2 Kegiatan Pelatihan manajemen tata kelola pada jurnal Lingkungan Fakultas Universitas Boyolali

Gambar 1. Merupakan photo bersama para pengelola jurnal dan rektor Universitas Boyolali yang dilakukan pada saat kegiatan sudah selesai dilaksanakan pada tanggal 23-7-2019. Gambar 2. Merupakan serah terima penghargaan berupa plakat dan sertifikat sebagai pembicara Pelatihan manajemen tata kelola pada jurnal Lingkungan Fakultas Universitas Boyolali pada tanggal 23-7-2019. Gambar 3. merupakan photo kegiatan sharing dan workshop manajemen tata kelola pada jurnal Lingkungan Fakultas Universitas Boyolali yang di ikuti oleh pengelola jurnal Universitas Boyolali yang dilaksanakan pada tanggal 22-72019.

\section{SIMPULAN}

Dengan dilaksanakan kegiatan sharing dan workshop manajemen tata kelola open journal system pada Jurnal pada Lingkungan Fakultas Universitas Boyolali, dapat meningkatkan pengetahuan tim jurnal sehingga dapat memahami konsep manajemen tata kelola open journal system, Mulai dari penyerahan (submit) naskah, review, editing, hingga publikasi naskah dengan simulasi dengan pada tim jurnal di lingkungan Fakultas Universitas Boyolali, saran untuk kegiatan pengabdian selanjutnya, dapat diberikan materi yang lebih 
advanced seperti pelatihan terkait standar akreditasi nasional dan cara mendaftar indeksasi skala sedang.

\section{UCAPAN TERIMAKASIH}

Terimakasih kepada Universitas Amikom Purwokerto yang telah memberikan pendanaan dalam pelaksanaan kegiatan Pengabdian Kepada Masyarakat ini, melalui Hibah Amikom Mitra Masyarakat (AMM) tahun 2019.

\section{DAFTAR PUSTAKA}

DIKTI. 2018. Peraturan Dirjen DIKTI Kementerian Pendidikan Nasional Republik Indonesia, tentang Akreditasi Terbitan Berkala Ilmiah. Jakarta.

Lukman. 2015. Aturan dan Perkembangan Jurnal Elektronik. Makalah Workshop Kesiapan Implementasi Pengelolaan Jurnal Secara Elektronik - LIPI, 26 Februari. Jakarta: PDIILIPI.

Permnristekdikti. 2018. Peraturan Dirjen DIKTI Kementerian Pendidikan Nasional Republik Indonesia, tentang Akreditasi Terbitan Berkala Ilmiah. Jakarta.

Wahid Nashihuddin, Dwiatri Kusumaningrum (2017). Manajemen Pengelolaan Jurnal Indonesia di PDII-LIPI. Simposium Nasional Simposium Nasional Perpustakaan PTKI STAIN Kediri. 